Empresas Familiares: Desafios à Gestão do Capital Humano

\author{
Duarte Pimentel ${ }^{1,2}$
}

${ }^{1}$ Willam James Center for Research, ISPA - Instituto Universitário

${ }^{2}$ TERINOV - Parque de Ciência e Tecnologia da Ilha Terceira 
"One of my key objectives is to ensure the family is proud of the company and feels a part of it. The moment the company becomes more of a financial investment for the family, we may as well go public, honestly. The family never sees the value of the equity because that gets passed on. We see ourselves simply as a steward of that equity as it moves from one generation to the next."

- H. Fisk Johnson, Chairman e CEO, S.C. Johnson \& Son (5 geração) (Wall Street Journal, 10 de Março de 2016).

\section{Empresas Familiares}

O conceito de empresa familiar inclui qualquer empresa em que uma família detém ou controla a propriedade do negócio, e no qual estão diretamente envolvidos dois ou mais membros da família (Brockhaus, 2004). É esta participação e influência da família nos negócios que diferencia estas empresas de todas as outras organizações. No entanto, caso exista um desvio neste padrão de propriedade e participação, as opiniões dos especialistas divergem sobre o que define uma empresa familiar. Assim, por forma a garantir a concordância sobre o conceito, as empresas familiares são por norma definidas como empresas controladas por uma família (por meio da maioria do direito de voto), onde a família está diretamente representada na equipa de gestão, e onde os representantes da família a identificam e percecionam como sendo uma empresa de cariz familiar (Westhead \& Cowling, 1998).

Do ponto de vista conceitual estas empresas podem ser entendidas como um híbrido contextual, isto é, uma combinação única de dois conjuntos distintos de regras, valores e expectativas: (1) os da família e (2) os da empresa (Tagiuri \& Davis, 1982). Por esta razão este tipo de empresas possui um conjunto de características que as tornam únicas em termos de padrões de propriedade, governança, tomada de decisão e estratégia (Pimentel, 2014; Pimentel, Scholten \& Couto, 2017; 2018). Desde há muito que é reconhecido que estas empresas (desde grandes multinacionais até ao pequeno negócio tradicional) têm uma forte orientação de longo prazo, colocando em primeiro plano os interesses alargados dos stakeholders (i.e., membros da família) em detrimento da mera obtenção de lucros. São estes padrões de regras, valores e expetativas, a forte orientação a longo prazo, e a preocupação genuína com as questões relacionadas com riqueza 
socioemocional que conferem às empresas familiares um conjunto de atributos que lhes permitem assumir um papel central no desenvolvimento socioeconómico mundial.

\section{Importância Socioeconómica}

As empresas familiares constituem a mais antiga e dominante forma de organização empresarial, e são os principais agentes do setor privado na economia mundial (Comi \& Eppler, 2014). Estas empresas, independentemente do sector de atividade, escala da operação, forma jurídica, ou do nível de desenvolvimento, desempenham um papel fundamental no crescimento socioeconómico de comunidades por todo o mundo. Dados da Family Firm Institute (2014) mostram que entre 80 e 95\% das empresas nos Estados Unidos e na América Latina, e mais de 80\% das empresas na Europa e na Ásia são controladas por famílias, representando mais de 50\% do PIB das principais economias mundiais, sendo, ainda, responsáveis pela maioria dos empregos criados (Poza, 2010). Nos países emergentes o impacto das empresas familiares é ainda maior, representando cerca de 70 a 90\% do PIB anual destas nações (McKinsey \& Co, 2014). Em Portugal, o retrato é em tudo semelhante, estima-se que mais de $70 \%$ das empresas sejam de cariz familiar, sendo responsáveis por $60 \%$ dos empregos, e por cerca de $50 \%$ da contribuição do setor privado para o PIB nacional (Family Firm Institute, 2014).

\section{Desafios à Gestão do Capital Humano}

À semelhança de todas as organizações, um dos aspetos críticos na gestão das empresas familiares prende-se com o capital humano. Em particular, no que respeita aos elementos que são parte da família mas de igual modo aos outros elementos, que ainda que não sejam parte da família, são essenciais para o sucesso destas organizações. Esta noção é corroborada por relatórios recentes da PwC (2018) que revelam que uma das maiores preocupações identificadas pelos líderes de empresas familiares relaciona-se com a atração, gestão e retenção de talentos, nomeadamente, no que respeita ao acesso às competências e capacidades certas. Ainda que este seja um desafio transversal a todas as organizações, é tão mais notório neste contexto uma vez que as empresas familiares têm uma preocupação assumida com a perpetuação do controlo familiar do negócio, o que 
muitas vezes dificulta os processos de gestão do capital humano. Em seguida, são identificados quatro grandes desafios intemporais da gestão do capital humano em empresas familiares para os quais torna-se necessário consciencializar os gestores:

\section{Nepotismo}

As empresas familiares são, na grande maioria dos casos, estruturadas como sociedades unipessoais ou parcerias entre membros de uma família. Quando é necessário contratar um novo colaborador ou promover alguém a um novo cargo, é prática comum oferecer a posição a um membro da família. Uma das principais preocupações a ter com o nepotismo é que muitas vezes este pode levar ao enfraquecimento da organização, pois favorece a escolha da pessoa tendo por base as suas relações familiares, em vez das competências ou do nível de qualificação para a função. Importa, no entanto, salientar que o nepotismo não é uma prática inerentemente negativa. Se a pessoa escolhida conhecer as necessidades da empresa e estiver devidamente preparada, pode desempenhar um papel vital e potenciar a riqueza de capital intelectual e de saber da família e da empresa. Por outro lado, caso essa pessoa não tenha qualquer interesse no negócio, nem as competências e qualificações necessárias, pode levar a que colaboradores extra-família altamente competentes, capazes e preparados se sintam preteridos e negligenciados, estando assim criadas as condições para quebras no compromisso desses colaboradores.

\section{Profissionalização}

Como referido anteriormente a necessidade/vontade de garantir a transição do controlo e gestão da empresa para a próxima geração é algo que está no ADN das empresas familiares. Neste sentido, a profissionalização da gestão das empresas familiares é um processo evolutivo fundamental para todas as empresas que procuram a sustentabilidade e o crescimento a longo prazo. Profissionalizar a gestão assenta na necessidade de transitar de um estilo de gestão familiar e informal para um estilo de gestão formal e criterioso que melhore as probabilidades de sucesso da empresa. Dito assim, este parece um processo relativamente simples e descomplicado, no entanto, a verdade é que muitas vezes a redefinição do modelo de gestão não se revela um processo fácil nem pacífico. Empresas familiares de sucesso procuram promover e potenciar ativamente este 
processo de transição, pois quando este é ignorado ou não é cuidadosamente preparado, resulta em caos no seio da empresa ou em sérios conflitos familiares. Não é por mero acaso que, à escala global, uma das principais prioridades dos líderes de empresas familiares é a profissionalização dos membros da família, por forma a torná-los mais capazes de conduzir o negócio de forma profissional, competente e capaz, garantindo consequentemente uma perpetuação suave e bem-sucedida para as gerações futuras.

\section{Conflitos Geracionais}

As empresas familiares combinam tipicamente várias gerações, com as gerações mais velhas sentindo-se intrinsecamente envolvidas no negócio, e em alguns momentos adoptando uma postura absolutista. Este forte envolvimento e a postura absolutista fazem com que novas ideias provenientes de familiares mais jovens sobre, por exemplo, como conquistar novos targets ou realizar as operações diárias de forma mais eficiente não sejam bem recebidas pelos membros seniores, que manifestam dificuldade em aceitar e integrar determinadas mudanças. Isto é particularmente verdade para empresas que transitaram de várias gerações anteriores, e que se confrontaram com poucas mudanças ao longo do tempo. Estas resistências à mudança podem rapidamente escalar para sérios conflitos geracionais à medida que os membros mais jovens da família vão assumindo posições com maior relevância e poder na empresa.

\section{Sucessão}

O risco de colapso da empresa devido à inexistência de um plano de sucessão tem sido identificado como uma das grandes fragilidades neste tipo de organizações. Dados recentes mostram que em Portugal $43 \%$ destas empresas não dispõem de qualquer tipo de plano de sucessão (PwC, 2016). No entanto, em muitos casos este plano de sucessão é inexistente não porque a necessidade não está devidamente identificada, mas porque a decisão sobre uma nova liderança pode ser uma fonte de fortes discórdias e divisões familiares. Ernesto Poza, uma das principais referências no estudo das empresas familiares, na obra Family Business (2010) sugere que apenas em 30\% dos casos a transição para a segunda geração família é bem-sucedida. Esta percentagem de sucesso é ainda mais baixa quando se trata da transição entre a segunda e a terceira geração (12\%). 
Se considerarmos a passagem da terceira para a quarta geração a taxa de sucesso fica-se por uns residuais $4 \%$. Estes números elucidam bem a necessidade de preparar e planear adequadamente a sucessão como forma de garantir a sobrevivência e sustentabilidade destas empresas.

A identificação destes desafios tem por objetivo trazer ao debate algumas das principais dificuldades na gestão do capital humano em empresas familiares, procurando ainda, de modo ambicioso, contribuir para que um ditado popular sobejamente conhecido neste contexto "Pai rico, filho nobre, neto pobre" seja cada vez menos aplicado à realidade.

\section{Referências}

Brockhaus, R. H. (2004). Family Business Succession: Suggestions for Future Research. Family Business Review, 17 (2), 165-177.

Comi, A., \& Eppler, M. J. (2014). Diagnosing capabilities in family firms: An overview of visual research methods and suggestions for future applications. Journal of Family Business Strategy, 5, 41-51.

Family Firm Institute (2014). Global data points disponível em https://my.ffi.org/page/globaldatapoints

McKinsey \& Company (2014). Perspectives on Founder- and Family-Owned Businesses disponível em https://www.mckinsey.com/industries/private-equity-and-principalinvestors/our-insights/perspectives-on-founder-and-family-owned-businesses

Pimentel, D. (2014). Defining and Characterizing Family Business in an Ultra-Peripheral Economic Context: Terceira Island, Azores. In Proceedings of the 20th APDR Congress. Pimentel, D. N. G. (2017). A family matter?: business profile decision and entrepreneurship in family business: the case of the Azores.

Pimentel, D. (2018). Non-family employees: levels of job satisfaction and organizational justice in small and medium-sized family and non-family firms. European Journal of Family Business, 8(2), 93-102. 
Pimentel, D. N. G., \& Scholten, M. (2017). Profiling family firms in the autonomous region of the Azores. Revista portuguesa de estudos regionais, (46), 91-107.

Pimentel, D., Scholten, M., \& Couto, J. P. (2017). Profiling family firms in the autonomous region of the Azores. Revista portuguesa de estudos regionais, 46, 91-107.

Pimentel, D., Scholten, M., \& Couto, J. P. (2018). Fast or slow? Decision-making styles in small family and nonfamily firms. Journal of Family Business Management, 8 (2), 113 125.

Poza, E. (2010). Family Business (3rd ed). Thomson South-Western.

PwC (2018). Inquérito Global sobre Empresas de Raiz Familiar 2018 disponível em https://www.pwc.pt/pt/temas-actuais/pwc-family-business-survey.pdf

Tagiuri, R., \& Davis, J. (1982). Bivalent attributes of the family firm (Working Paper, Harvard Business School, Cambridge). Reprinted 1996, Family Business Review, 9 (2), 199-208.

Westhead, P., \& Cowling, M. (1998). Family firm research: the need for a methodological rethinking. Entrepreneurship, Theory and Practice, 23, 31-56. 